\title{
Research of Context-oriented Adaptive Content Framework in Seamless Learning
}

\author{
ZHONG Qiuyan, LIU Xiaodong \\ Faculty of Management and Economics \\ Dalian University of Technology \\ Dalian,China \\ e-mail: zhongqy@dlut.edu.cn,lxd@dlnu.edu.cn
}

\author{
JI Shaobo \\ Sprott School of Business \\ Carleton University, Canada \\ Ottawa,ON,Canada \\ e-mail: sji@business.carleton.ca
}

\begin{abstract}
The direct driving force of the research and development of mobile learning comes from the advances in mobile communication technology. However, it's far from enough that we improve learning experience depending on new technology alone. The biggest difference between m-learning and traditional e-learning is from the change of context which is brought by mobility. Therefore context adaptation seems especially important to m-learning. This paper presents a framework to describe the factors that play an important role in delivering learning content to mobile learners, and their relationship to each other. The system constructs learner models by processing personalized information, reorganizes learning materials with adaptation labels or learning units, and generates learning content according to individual learner model so as to meet the specific personal needs.
\end{abstract}

Keywords- seamless learning, context, adaptation, learner model, learning content

\section{INTRODUCTION}

At the tenth M-Learn World Conference in 2011, "Seamless Learning" is brought up again, which resonates among the experts and scholars. They agree to take seamless learning as in-depth development direction of m-learning [1]. Compared with m-learning, seamless learning is more adaptive to context, and create a seamless learning space and continuous learning experience for learner through perception and feedback of changing context.

Mobile learning needs to pay special attention on "context". Context is a key clue of seamless learning based upon mobile technology and also a promising field of $\mathrm{m}$ learning in the future (Sharples, 2011). Intelligent adaptability of mobile technology based context-awareness in seamless learning space, especially enhancement of selfadaptability of m-learning system, is mainly presented in two aspects: one is right context-awareness; the other is to process and utilize context-aware information intelligently to provide appropriate learning support services for learner ( Kinshuk, 2011).

In recent years, although "context-aware ability" of mobile technology obtained constant development, that how to collect, process and use changing information of context awareness intelligently and then present and generate personalized learning content and learning guidance dynamically to meet the various requirements of learners is still faced with many challenges. Fischer stated [2]: "the challenge in an information-rich world is not only to make

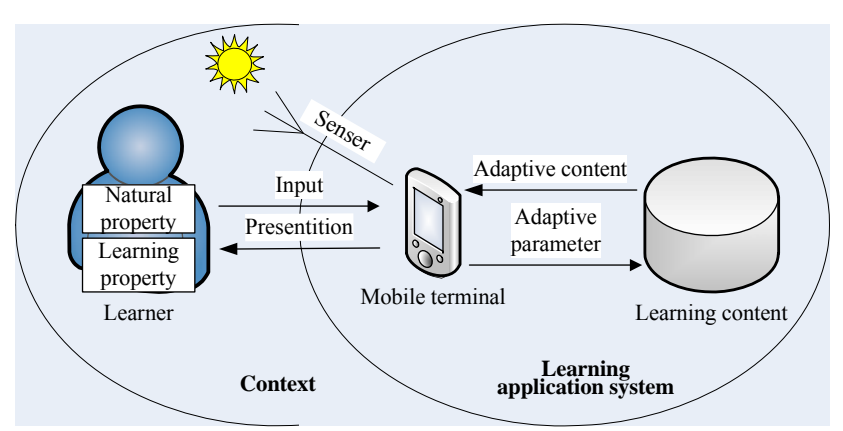

Figure 1. Context oriented content-adaptive construction in seamless learning

information available to people at any time, at any place, and in any form, but specifically to say the right thing at the right time in the right way". This paper not only considers the context analysis of m-learning and learner model construction but also presents a framework of learning content adaptation. Fig. 1 is a content-adaptive construction which is constituted by the interactions between context and learning system in mobile learning, which is also the overall structure of this paper.

\section{RETROSPECT OF CONTEXT ADAPTATION- BASED M-LEARNING RESEARCH}

Numerous projects attempting to implement m-learning in very specific contexts have been undertaken in recent years all over the world[3]. These projects have had varied aims and levels of adaptation for individual users. There have also been many projects concerned primarily with context awareness and its impact on content delivery. A sample of such projects is listed below.

- Harri Ketamo from Tampere University of Technology presented geometry learning in the form of a game in which the electronic device was used to measure each student's knowledge level, and then adapted the speed of presenting new learning material to meet the needs of different learners. He also developed an m-learning environment which can adapt to different terminal devices (PC, PDA and WAP) [4] [5].

- The Kidsroom project at MIT Media laboratory provided a room in which children were guided through an interactive storytelling game. Materials were adapted according to the activity context [6]. 
- Hiroaki Ogata and Yaeno Yano from Tokushima University designed a context-aware language learning support system for learning Japanese honorifics [7].

- $\quad$ The MOBIlearn project of EU developed a universal interaction system in which information about user is collected through sensor and transmitted to responding services. An adaptive learning interface system has also been developed within the project [8].

Most of these projects listed above have been concerned with the impact of context in relation to m-learning, but they mainly concentrated on the technology level and did not address individual context of mobile learner and the importance of learning content in terms of adaptation techniques. Therefore, it is of great significance to learn from these achievements and study learning content adaptation according to learner model for constructing seamless learning environment.

\section{CONTEXT CLASSIFICATION OF MOBILE LEARNING AND BASIC PROCESS OF CONTENT ADAPTATION}

Dey, Abowd and Salber define context as "any information that can be used to characterize the situation of an entity. An entity is a person, a place, or an object that is considered relevant to the interaction between a user and an application, including the user and the application themselves"[9]. Dey [10] believes that necessary context information includes position, infrastructure or resource, user, situation, entity and time; Liberman et al [11] think that context information can be summarized in three aspects: user, situation and application; YUE Weining et al.[12]suppose that context information can be broadly classified into three categories: natural environment, device environment and user environment. GU Junzhong [13] brings forward the concept of "context pedigree", and suggests that context consists of computing context, user context, physical context, time context and social context; Shilit [14] divided context into three categories: computing context, learner context, and physical context. Different classification methods focus on different points and have different granularities, but their basic contents converge. This paper adopts Shilit's basic context classification and even classifies in detail. The classification of m-learning context factors is shown in Table 1. The specific instructions are as follows.

Context factors of learners include personal natural property (e.g. age, gender), social property (e.g. group, family) and property that is directly relevant to learning (e.g. learning basis, cognitive ability, learning styles/preferences). Computing context refers to device and application service that are relevant to the current task that a learner does in $\mathrm{m}$ learning, which include device type, device parameter and functional state that the applications provide etc. Physical context depicts the characteristics of user's current situation, including natural environment (e.g. position, temperature) and social environment (e.g. language, customs).

Context awareness is the basis of learning adaptation.
TABLE I. CLASSIFICATION OF M-LEARNING CONTEXT FACTORS

\begin{tabular}{|c|c|c|c|}
\hline $\begin{array}{c}\text { Basic } \\
\text { context }\end{array}$ & Classification & Examples & $\begin{array}{c}\text { Basic } \\
\text { collecting } \\
\text { method }\end{array}$ \\
\hline \multirow[t]{3}{*}{$\begin{array}{l}\text { Learner } \\
\text { context }\end{array}$} & $\begin{array}{l}\text { Natural } \\
\text { property }\end{array}$ & $\begin{array}{l}\text { Age,gender,height, weight, } \\
\text { physical condition, level } \\
\text { of education }\end{array}$ & Input \\
\hline & $\begin{array}{c}\text { Social } \\
\text { property }\end{array}$ & Class,family,organization & Input \\
\hline & $\begin{array}{l}\text { Learning } \\
\text { property }\end{array}$ & $\begin{array}{l}\text { learning basis, cognitive } \\
\text { ability,learning style }\end{array}$ & $\begin{array}{l}\text { data } \\
\text { mining } \\
\text { reasoning }\end{array}$ \\
\hline \multirow[t]{2}{*}{$\begin{array}{l}\text { Physical } \\
\text { context }\end{array}$} & $\begin{array}{c}\text { Natural } \\
\text { environment }\end{array}$ & $\begin{array}{c}\text { Position,time,noise } \\
\text { Temperature,light, weather }\end{array}$ & Automatically \\
\hline & $\begin{array}{c}\text { Social } \\
\text { environment }\end{array}$ & Language, customs, law & data mining \\
\hline \multirow[t]{2}{*}{$\begin{array}{l}\text { Computing } \\
\text { context }\end{array}$} & $\begin{array}{c}\text { Device } \\
\text { environment }\end{array}$ & $\begin{array}{c}\text { Device type,technical } \\
\text { parameter,network type, } \\
\text { network speed }\end{array}$ & Automatically \\
\hline & $\begin{array}{c}\text { Program } \\
\text { environment }\end{array}$ & program function,edition & Automatically \\
\hline
\end{tabular}

The adaptation processing of context-aware m-learning system is to collect, classify, filter and contract information of the three contexts mentioned above, to form adaptive information taken as input of learning content generating system and ultimately forming personalized learning content for specific users. The core tasks of the process are learner modeling and adaptation processing of learning content. These will be discussed respectively below.

\section{LEARNER MODELING}

\section{A. Learner model}

Learner model standard talks about the data exchange of learner information. E-learning based learner model has been defined in the form of information standard by many international organizations and countries. Such as IEEE1484.2 standard of IEEE Learning Technology Standards Committee (LTSC) and Information Management System (IMS) standard formulated by The United States International Learning Association. Learner Model Standard CELTSC-11 formulated by Chinese e-Learning Technology Standardization Committee divides learner information into eight categories: personal, study, management, relation, safety, preference, achievement and portfolio [15].

To construct learner model in m-learning form by synthesizing and extending above classifications, model parameter can be classified into four categories considering its implementability:

- Learner property. It comes from learner's natural property and social property, and corresponds to personal information, relation information, safety information and management information.

- Environment property. It comes from physical context and computing context. This property is a extended property of m-learning which is not contained in the standards mentioned above.

- Learning basis. It refers to learner's mastery of knowledge that they have acquired and learner's self-adjustment and techniques to cognitive activities. It contains knowledge level and cognitive ability and comes from learning property in learner's context. It can be acquired through specific test, and 
corresponds to studies information, performance information and portfolio information in CELTSC.

- Learning styles. Keefe defined learning styles as "cognitive, affective and physiological personality traits, which represent a relatively permanent indicator of how learners perceive and how they deal with the environment, which serves as a source of knowledge." [16]. It also comes from learning property in learner's context, and can be acquired by recording, data mining, reasoning and hypothesizing learning process. It responds to preference information in CELTSC.

The four properties constitute leaner model defined in this paper. Because of the complex relation between learners and context, machine learning related theories and technologies are often used on many fields like modeling learners, making assumptions about specific learners through reasoning methods, interactions between learners and study system, constructing learner model, neural network, KNN (k-Nearest Neighbors), Bayesian network and fuzzy algorithm, and so on.

\section{B. Obtainment of context parameter}

Collecting context parameter is the base of learner modeling and learning content processing. Context information can be explicit or implicit, which can be acquired in direct or indirect ways. Explicit information is often acquired by means of registering, optioning and filling in the form of text boxes and check boxes. Implicit information is gathered by various sensing equipments, or by users' questionnaires, testing, analyzing and mining of learning records, and further assuming users' states, motivations, needs and so on. Implicit information collecting includes sensor collecting, system journal analysis and so on. The information that learners have input and the descriptions to current context are the most direct and effective ways in evaluating context. However, a good learning system should reduce its dependence on users input, because in m-learning context the input capacity of terminal devices is limited, therefore, reducing learners input would greatly improve user's experience of the system.

Under initial state, learner context parameter can be acquired in three ways: the first is registered information. System should collect as much information about a new user as possible, for user's registration is the effective way. The second is questionnaire. It means to acquire learner's general and specific characteristics by analyzing their answers to the questionnaire questions set by the system. The third is test, which can be done when learners use the system at the first time or during the process. By way of testing, system can obtain information about learners's learning condition and their cognitive ability, and then evaluate and calculate these information. Collecting parameters of learning styles and learning preferences can be done in two ways: collecting parameters by copying the methods mentioned above; analyzing the records of learners' learning behaviors and their interactions with the system.

Physical context collecting primarily relies on the sensing device in m-learning devices. For instance, location data can be acquired by GPS and some other wireless network positioning technologies; and time, environment temperature, light and noise intensity can be acquired by clock, temperature sensor, light sensor and microphone that are built in the device.

It must be pointed out that in certain circumstances, more learner context information cannot be acquired directly by means of learner input and sensor. Under this condition, an supposed initial parameter can be set, which would dynamically modify during the learning process by other ways of input.

\section{ADAPTATION PROCESSING OF LEARNING CONTENT BASED ON CONTEXT}

Adaptation processing of learning content includes two phases: constructing phase by instructors and processing phase by machines. First, instructors need to preprocess teaching material during the input phase of teaching content, which is the foundation for adaptation calculating of learning system. Then, the preprocessed learning resources will generate personalized content through reasoning and matching by the machine according to current learner model, and then transmits the personalized content to learners, thus an adaptation processing of context based learning content is completed. As is shown in Fig2.

\section{A. Instructor phase of content adaptation}

Learning content derives from instructors. It presents various forms like texts, pictures, animation, videos, audio, and we call them learning materials. Learning materials are input into the system through constructing, importing or entering. Instructors (content managers) classifie or combine current materials or saved teaching materials, and develop them into learning unit, the smallest unit for learning. Learning content unit refers to a structured learning material collection which is of great significance in learning for learners and can be evaluated. A learning unit could be test questions composed of numerous words, or a background information theme composed of pictures and videos.

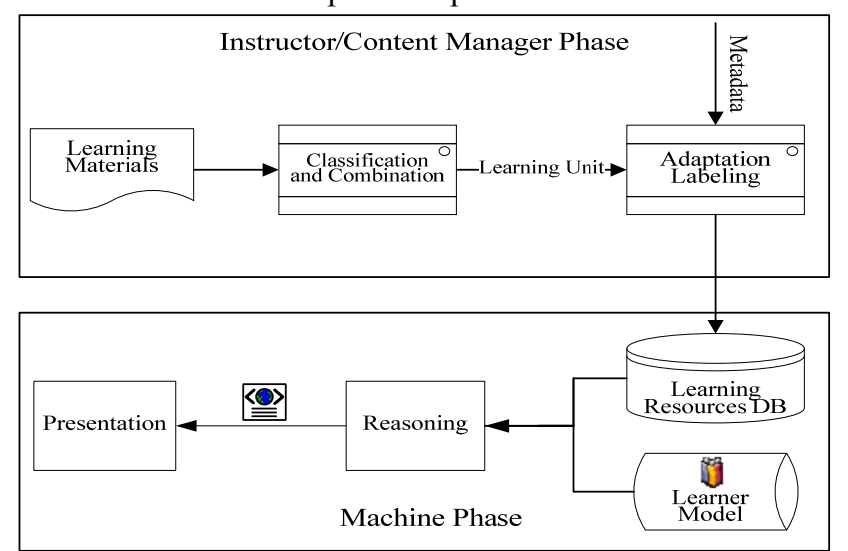

Figure 2. context-based content-adaptive processing

A simple learning unit cannot be used to complete context adaptive learning tasks, therefore, processing of metadata labeling is needed. Instructors or content managers 
can label the materials through the interface provided by the system. During the process, instructors should answer the following questions and conduct corresponding operations: Which learning theme does this unit serves for? What are the appropriate physical contexts (e.g. classroom, outdoor, mobile environment) for the unit? What kind of specification and parameter (resolution, computing speed) of mobile devices are required by it? What is its appropriate learning time? What kind of learners (1st-5th level) is suitable for is? Which kind of abilities of learners does it aim to train or facilitate? To which level (1st-5th level) or to what kind of learners with specific learning preferences (attending lectures, doing research or collaborating with instructors) does it fit? Label processing of learning content unit is a manual procedure, and there are a lot of points to be labeled. It is, therefore, the fundamental work for constructing adaptive system. The system should provide operators a friendly and convenient human-computer interface, as for some parameters, the system can automatically generate initial value. For instance, reading texts and learning time can be generated through calculating according to the number of characters; for some labeling items, system can record and count the parameters of similar contents that different teachers have input based on the methods of statistics. The recommended value will be available when needed, which will bring great convenience for teachers to operate.

After the adaptability label processing, learning content will be kept in the learning content database, which is available for learning management system and adaptability processing procedure. . . . 1

\section{B. Machine phase of adaptive content}

Once an individual learner model is established, the reasoning module of the system will extract learners' needs, then adaptation learning content can be generated by means of comparing, matching and recombining the eigenvalue sequences of learner model with that of learning content in learning database, and then submit the adaptation learning content to the learner, thus an entire adaptation learning process is completed.

Content recommendation algorithm has been widely used in various applications especially in e-commerce. Many comparatively mature recommendation algorithms have appeared, such as various collaborative filtering algorithms (e.g. user rating-oriented, program-oriented, program rating prediction-oriented), semantic distance, nearest neighbor, Bayesian networks technology, clustering technology, association rules technology and Horting Technology. These algorithms have their own characteristics and limitations in different application backgrounds, but their detailed information is not discussed in this paper.

The description mentioned above is about a contextawareness based intelligent adaptation processing procedure of m-learning. On the other hand, the adaptation of learning content is also an interest and preference based selective process of learners, which can be launched by themselves. Learning system should fully consider this two-way choice mechanism.

\section{CONCLUSION}

This paper presents an m-learning framework of processing learning content to meet learners' different characteristics and needs based on learner model through fully analyzing context factors of m-learning. By interactions among the five factors learner, instructor, learning content, learning context and learning system to meet the personalized needs of learner in seamless learning, this framework makes learning very learner-centric. Personalized learning content processing method makes aptitude-based teaching in mobile learning possible.

\section{REFERENCES}

[1] LIU Jun,QIU Qin,YU Shengquan and XI Jianhua, "Technology,Resources,and Learning Innovations of Seamless Learning Space: Review of the 10th World Conferenceon Mobile and Contextual Learning," Open Education Research, 2011( 5),pp.8-19.

[2] G. Fischer,"User Modeling in Human-computer Interaction",User Modeling and User- Adapted Interaction 11(1and2),2001.pp. 65-86.

[3] Al-Hmouz. A and Freeman.A, "Learning on Location: An Adaptive Mobile Learning Content Framework," 2010 IEEE International Symposium on Technology and Society,pp.450-456.

[4] Ketamo H,"mLearning for kindergarten's mathematics teaching," Proceedings of IEEE International Workshop on wireless and Mobile Technologies in Education,pp. 167-170,Sweden,August 2002.

[5] H. Ketamo,"Xtask - adaptable working environment," In M. Milrad,H. U. Hoppe,and Kinshuk,editors,WMTE,pp. 55-62. IEEE Computer Society,2002.

[6] Bobick A F,Intille S S,Davis J W,Baird F,Pinhanez C S,Campbell L W,Ivanov Y A,Schutte A,and Wilson A, "The KidsRoom: a perceptually-based interactive and immersive story environment," MIT Media Laboratory perceptual Computing Section Technical Report No.398,November 1996,revised June 1998.

[7] H. Ogata and Y. Yano,"Context-aware support for computer supported ubiquitous learning",In J. Roschelle,T.-W. Chan,Kinshuk,and S. J. H. Yang,editors,WMTE,pp. 27-34,2004.

[8] A. Syv"anen,R. Beale,M. Sharples,M. Ahonen,and P. Lonsdale,"Supporting pervasive learning environments: Adaptability and context awareness in mobile learning," In WMTE,pp. 251253,2005 .

[9] A.K. Dey,G.D. Abowd,D. Sabler,"A conceptual framework and a toolkit for supporting the rapid prototyping of context-aware applications," Human-Computer Interaction, 16(2/4): pp. 97-166,2001.

[10] DEY A K."Providing architectural support for building context aware applications," Atlanta: Georgia Institute of Technology,2000.

[11] Lieberman H,Selker t, "Out of context: computer systems that adapt to,and learn from,context,"IBM Systems Journal, 2000,39( 3/4), pp.617-632.

[12] YUE Weining, DONG Shihai, WANG Yue, WANG Guoping and WANG Heng et al., "Study on Human-Computer Interaction Framework of Pervasive Computing", Chinese Journal of Computers, Vol. 27 No.12,Dec. 2004 pp.1657-1664

[13] GU Junzhong. "Context aware computing," Journal of East China Normal University(Natural Science), No.5 Sep.t ,2009,pp.1-20.

[14] B. N. Schilit. "A System Architecture for Context-Aware Mobile Computing",PhD thesis, 1995.

[15] China information technology standardization committee,CELTS-11, learner Model specifications.

[16] Keefe, J.W.. "Learning style theory and practice," Reston: National Association of Secondary School Principals. 1987. 